\title{
A rough set-based supplier evaluation method
}

\author{
Wenpeng WANG \\ Department of Logistic Management \\ Qingdao University of Science and Technology \\ Qingdao, China \\ wawapa@gmail.com
}

\author{
Junhong LIU \\ Qingdao University of Science and Technology \\ Qingdao, China \\ Xinning YU \\ Qingdao University of Science and Technology \\ Qingdao, China
}

\begin{abstract}
In order to overcome the subjective and inefficiency of the traditional supplier evaluation and decision methods, it adopts rough set theory as the tool of supplier evaluation method. It established a rough set-based supplier evaluation procedure according to the sequence of data acquisition, attribute reduction, rule extraction, weight design, and comprehensive assessment. The effective and efficient of this method is proofed by real case from a tire plant.
\end{abstract}

Keywords-Supplier evaluation; Rough set theory; Attribute reduction

\section{INTRODUCTION}

In order to reduce supply risks, improve operational efficiency, the enterprises in the supply network demand to evaluate their suppliers to assist in decision-making ${ }^{[1]}$. The traditional supplier evaluation methods mainly include three types: Qualitative evaluation method of Financial methods, Management by Objective, Quantitative evaluation method of $\mathrm{ABC}$, multi objective programming approach, analysis hierarchy process, and comprehensive evaluation system of balanced score card. All these methods have advantages of simple, easy to understand, but also disadvantages of evaluate standards unitary, solution process complicated, In particular, the analysis of the data is usually dependent on the tacit knowledge, and has a strong subjectivity ${ }^{[2]}$.

In order to avoid the influence of subjective factors on the evaluation process and results, it shall handle massive amounts of information by means of some kind of objective data analysis method, and find the inner knowledge and laws through the surface information, so as to make an objective and effective evaluation to the value of each supplier ${ }^{[3]}$. The paper tries to establish a new rough set-based supplier evaluation procedure. Rough set theory uses the mathematical method to analysis and process the object, without depending on the tacit knowledge, to avoid the influence of subjective factors efficiently. Through using the advantage in data reduction and rule extraction of Rough set theory, it can dig knowledge and risk rules with high credibility from the database, and help the managers using the existing data sample to evaluate the suppliers subjectively.

\section{BASIC KNOWLEDGE OF ROUGH SET THEORY}

Rough set theory was a data analysis method proposed by Pawlak in 1982, commonly used in describing and processing the problems with the characteristics of uncertainty and incomplete ${ }^{[4]}$. Because there is no need to provide any priori information besides the required processing data collection, and also the advantages in attribute reduction, rule extraction, it applies to process both redundancy and missing features of the original data needed for evaluating suppliers, find the internal changes in laws of a variety of data, and measure the importance of various factors.

In the existing related studies, Yu Xin, Wang Daoping, Huang Zhexue accessed supplier performance through the rough set method under the electronics supply chain environment ${ }^{[5]}$. They conducted a comprehensive evaluation of the multi-level multi-angle evaluation attributes, which ensured the objectivity of the evaluation results, and comprehensive conclusions could be drawn through progressively projections of different levels of evaluation factors. Shao Liangshan, Qiu Yunfei, Du Wentao established the comprehensive evaluation index system of suppliers, and established a rough set-based supplier evaluation selection model, making use of the rules extraction technology and knowledge base construction techniques of the rough set theory ${ }^{[6]}$. Compared with them, this paper focuses on the implementation process of the supplier evaluation method based on rough set theory, and the application detail of rough set standard processing mode such as attribute reduction, significance of definition in the actual information processing. The effective and efficient of this method is proofed by real case from a tire plant.

\section{SuPPliER Evaluation Procedures}

\section{A. Selecting a Template (Heading 2)}

Using rough set as the tool of supplier evaluation decision-making model, we can transform the massive data into classification rule, in order to analysis the data and find useful information better.

The specific implementation points include:

Step 1: The supplier evaluation index system required is the present situation of enterprises.

Step 2: See each index as condition attribute, assume that there are $n$ condition attributes and $m$ evaluation objects, and construct the $m \times(n+1)$-order original decision table of rough set.

Step 3: Delete redundant index from the index system, and retain the key index, to form a new simplified index 
system, and get the final decision table, and get the supplier decision rules from the final decision table.

Step 4: Calculate the weight of every index(attribute) in the final decision table according to the definition of significance of attributes. Assuming that $D T=(U, R, D, V, f)$ for the final decision table, then for any $c_{i} \in R$, calculation formula of the weight $w_{i}$ of $c_{i}$ is:

$$
w_{i}=\frac{\operatorname{SGF}\left(c_{i}, \mathrm{R}, \mathrm{D}\right)}{\sum_{j=1}^{n} \operatorname{SGF}\left(c_{j}, \mathrm{R}, \mathrm{D}\right)} \text {, where } n=|R| \text {. Obviously } 0 \leq
$$

$w_{i} \leq 1$

Step 5: Calculate the value of the supplier with $V_{j}=\sum v c_{i j} w_{i}$, where $c_{i j}$ means the value of the $j$-th supplier in the $i$-th index, $w_{i}$ is the weigh of the $i$-th index.

\section{EXPERIMENTS AND RESULTS}

\section{A. Establish the supplier initial evaluation index system} and the initial decision table.

We gather large amount of original data by a follow-up survey of eight major suppliers of a tire companies. The paper designs an index system consists of two categories seven conditions by the analysis of these data: Product index and Production system index.

Through the induction and consolidation of the above index system, the paper selects five condition attributes(production flexibility, delivery time, market share, the degree of informatization construction and equipment advanced, the price-to-quality ratio of the product).The supplier initial decision table is established, where:

(1) the universe $\mathrm{U}=\{\mathrm{S} 1, \mathrm{~S} 2, \mathrm{~S} 3, \mathrm{~S} 4, \mathrm{~S} 5, \mathrm{~S} 6, \mathrm{~S} 7, \mathrm{~S}$ $8\}$,,where Si means the i-th supplier.

(2) condition attributes $\mathrm{C}=\{\mathrm{c} 1, \mathrm{c} 2, \mathrm{c} 3, \mathrm{c} 4, \mathrm{c} 5\}$, where $\mathrm{c} 1$ means production flexibility(divides into emergency distribution, emergency distribution in most cases, generally doesn't provide emergency distribution three levels), c2 means the nature of delivery time(divides into delivery on time, occasional delay in delivery, often delay in delivery),c3 means market share(facing the many enterprises, facing some enterprises, provide raw materials to only a few enterprises),c4 means the degree of informatization construction and equipment advanced, c5 means the price-toquality ratio of the product.

(3) the decision attributes $\mathrm{D}=\{\mathrm{d}\}$ mean the supplier evaluation category.

TABLE I. THE SUPPLIER INITIAL DECISION

\begin{tabular}{ccccccc}
\hline \multirow{2}{*}{ Supplier $S$} & $c_{1}$ & $c_{2}$ & $c_{3}$ & $c_{4}$ & $c_{5}$ & Decision \\
& bad & good & good & middle & good & good \\
\hline$S_{1}$ & bad & good & good & middle & bad & middle \\
$S_{2}$ & bad & good & good & middle & good & good \\
$S_{3}$ & middle & bad & middle & middle & middle & bad \\
$S_{4}$ & middle & bad & middle & middle & good & middle \\
$S_{5}$ & good & bad & bad & good & bad & bad \\
$S_{6}$ & good & middle & bad & good & bad & middle \\
$S_{7}$ & middle & good & middle & middle & middle & middle \\
$S_{8}$ & & & & & & \\
\hline
\end{tabular}

B. Get the final decision table after attributes reduction, and the supplier evaluation rules.

Deal with the initial decision table with the above steps, first of all, calculate the partition of the univers $U$ according to the condition attributes and the decidion attributes respectly.

And then calculate positive region according to the result of the partition.

According to the above results, the D-reduction of $\mathrm{C}$ is $R$ $=\left\{c_{2}, c_{5}\right\}$, we get the decision table after reduction..

TABLE II. THE DECISION TABLE AFTER REDUCTION

\begin{tabular}{|c|c|c|c|}
\hline \multirow[t]{2}{*}{ Supplier $S$} & \multicolumn{2}{|c|}{$\begin{array}{c}\text { Index system } \\
\text { (Condition Attributes) }\end{array}$} & \multirow{2}{*}{$\begin{array}{c}\text { Decision } \\
\text { Attributes } D\end{array}$} \\
\hline & $c_{2}$ & $c_{5}$ & \\
\hline$S_{1}$ & good & good & good \\
\hline$S_{2}$ & good & bad & middle \\
\hline$S_{3}$ & good & good & good \\
\hline$S_{4}$ & bad & middle & bad \\
\hline$S_{5}$ & bad & good & middle \\
\hline$S_{6}$ & bad & bad & bad \\
\hline$S_{7}$ & middle & bad & middle \\
\hline$S_{8}$ & good & middle & middle \\
\hline
\end{tabular}

After getting rid of the redundant attributes, we need only two index (the nature of delivery time, the price-toquality ratio of the product) to evaluate the supplier, so as to improve the efficiency of the evaluation effectively.

For each row in the decision table after reduction, we can obtain the evaluation rules as follows:

$R 1:$ IF $c_{2}=\operatorname{good} \wedge c_{5}=\operatorname{good}$ THEN $D=\operatorname{good}$, $R 2:$ IF $c_{2}=\operatorname{good} \wedge c_{5} \neq$ good THEN $D=$ middle,

R3: IF $c_{2}=$ middle $\wedge c_{5}=$ bad THEN $D=$ middle, R4: IF $c_{2}=$ bad $\wedge c_{5}=$ good THEN $D=$ middle,

R5: IF $c_{2}=$ bad $\wedge c_{5} \neq$ good THEN $D=b a d$.

The rule $R_{1}$ means: delivery on time, and the suppliers of high price-to-quality ratio are all of high-valued. The explanation of other rule is similar to $R_{1}$. The evaluation rule will be stored in the knowledge base under the premise of keeping the original information unchanged. We just need to match all aspects of the new supplier with these rules so as to evaluate the value of the supplier later in the supplier evaluation decision.

C. Calculate the weight of each attribute in the final decision table according to the definition of the significance of attributes.

First of all, calculate the significance of each attribute:

$$
\begin{aligned}
& S G F\left(c_{2}, R, D\right)=\frac{\operatorname{pos}_{R}(D)-\operatorname{pos}_{\left(R-\left\{c_{2}\right\}\right)}(D)}{|U|}=\frac{8-4}{8}=\frac{1}{2}, \\
& S G F\left(c_{5}, R, D\right)=\frac{\operatorname{pos}_{R}(D)-\operatorname{pos}_{\left(R-\left\{c_{5}\right\}\right)}(D)}{|U|}=\frac{8-3}{8}=\frac{5}{8},
\end{aligned}
$$

Calculate the weight $w_{2}, w_{5}$ of $c_{2}, c_{5}$ respectively: 


$$
w_{2}=\frac{S G F\left(c_{2}, \mathrm{R}, \mathrm{D}\right)}{\sum_{j=1}^{2} S G F\left(c_{j}, \mathrm{R}, \mathrm{D}\right)}=\frac{4}{9}, w_{5}=\frac{S G F\left(c_{5}, \mathrm{R}, \mathrm{D}\right)}{\sum_{j=1}^{2} S G F\left(c_{j}, \mathrm{R}, \mathrm{D}\right)}=\frac{5}{9} .
$$

D. Evaluate the value of suppliers.

The paper will convert the qualitative assessment level of index into the corresponding score: \{good, middle, $\mathrm{bad}\}=\{1.0,0.5,0.0\}$.So we can get the decision table after index quantification.

TABLE III. THE DECISION TABLE AFTER REDUCTION

\begin{tabular}{ccccccc}
\hline \multirow{2}{*}{ Supplier $S$} & \multicolumn{5}{c}{ Index system(Condition Attributes) } & Decision \\
& $c_{1}$ & $c_{2}$ & $c_{3}$ & $c_{4}$ & $c_{5}$ & Attributes $D$ \\
\hline$S_{1}$ & 0.0 & 1.0 & 1.0 & 0.5 & 1.0 & 1.0 \\
$S_{2}$ & 0.0 & 1.0 & 1.0 & 0.5 & 0.0 & 0.5 \\
$S_{3}$ & 0.0 & 1.0 & 1.0 & 0.5 & 1.0 & 1.0 \\
$S_{4}$ & 0.5 & 0.0 & 0.5 & 0.5 & 0.5 & 0.0 \\
$S_{5}$ & 0.5 & 0.0 & 0.5 & 0.5 & 1.0 & 0.5 \\
$S_{6}$ & 1.0 & 0.0 & 0.0 & 1.0 & 0.0 & 0.0 \\
$S_{7}$ & 1.0 & 0.5 & 0.0 & 1.0 & 0.0 & 0.5 \\
$S_{8}$ & 0.5 & 1.0 & 0.5 & 0.5 & 0.5 & 0.5 \\
\hline
\end{tabular}

Finally we get the set of the comprehensive score of the eight suppliers: $\{1.0,0.44,1.0,0.28,0.56,0.0,0.22,0.72\}$. It can be seen that the order of the value of the eight suppliers is that $S_{1}=S_{3}>S_{8}>S_{5}>S_{2}>S_{4}>S_{7}>S_{6}$. The priority relations can be used as the reference for the manager to select the suppliers: select supplier $S_{1}$ or $S_{3}$ as a priority, then followed by $S_{8}$ etc. The supplier evaluation result obtained using this method is consistent with the reality.

\section{CONCLUSIONS}

This paper analyses a number of factors that affected the value of the suppliers, and reduces them to several core indexes, using the significance of attributes formula of rough set to calculate their weights, realizing the evaluation of the value of the supplier. It adopts rough set theory as the tool of supplier evaluation method, which doesn't need a lot of prior knowledge, and completes the screen of a variety of indexes, and also simplifies the complexity of the operation. Finally the effective and objective of this method is proofed by the actual data from a tire plant.

\section{REFERENCES}

[1] Ma Li-juan. Supply chain management-based supplier selection: a tentative exploration [J]. Industrial Engineering and Management, 2002.7:274-275.

[2] Robert Menard. Supplier evaluation takes more than a pulse and price [J]. American Purchasing Society, 2009.11:7-15.

[3] Li Yuanyuan, Yun Jun. Comprehensive Evaluation Method Based on Rough Set [J]. Journal of Wuhan University of Technology (Information \& Management Engineering), 2009.12:981-985.

[4] Wang Guo-yin, Yao Yi-yu, Yu Hong. A Survey on Rough Set Theory and Applications [J], Chinese Journal of Computers, 2009.7:12291246.

[5] Yu Xin, Wang Dao-ping, Huang Zhe-xue. Research on Supplier's Performance Evaluation Model in E-supply Chain Environment [J]. Soft Science, 2007,21:221-222.

[6] Shao Liang-shan, Qiu Yun-fei, Du Wen-tao. Supplier evaluation and selection based on rough set [J]. Journal of Liaoning Technical University(Natural Science), 2008,10:272-273.

\section{BIOGRAPHY}

WANG Wenpeng (1976.1-), Jiangsu Province, PH.D, College of Economy and Management Qingdao University of Science and Technology.

Mobile:15954809133 Email:wawapa@gmail.com

\section{FOUNDATION ITEM}

Project supported by the Youth Scientists Award Fund of Shandong(BS2012ZZ003) and Humanities and Social Science Fund of QUST (11XB02) 